\title{
Utilizing Artistic Reactions in Research: Elevating Affective Data
}

\author{
Joanna Klingenstein \\ Department of Religious Studies, Case Western Reserve University, Cleveland, United States of America, \\ Joanna.Klingenstein@case.edu
}

\begin{abstract}
Rarely does research design rely on the use of artistic processes to gather affective data. Scholars often rely on verbal communication to measure affective response rather than extracting data through creative mediums. Art therapists have long been writing about the power of creativity to uniquely surface emotion. Do artistic processes tap into affective data otherwise ignored? Can affective response further academic knowledge of power and influence? As noted by scholar and theorist Donovan Schaefer, affect theory highlights associations between semiotic forces and power. It offers a framework for understanding how emotional responses are shaped and experienced. Similarly, the Expressive Therapies Continuum (ETC), developed by art therapy pioneers Sandra Kagan and Vija Lusebrink, suggests a way to visualize expression according to the placement of affect in the body. The ETC therefore allows art therapists to guide and interpret creative processes. In a study titled, "Female Evangelical Multimedia Personalities: How Does Their Content Affect Female Viewers?" these theoretical frameworks are combined in a way that, to this author's knowledge, has not been done before. As part of the study design, participants will be asked to react artistically and verbally to written and visual evangelical content. This study seeks to illuminate how artistic processes expose the affective influence and power of rhetorical content. The proposed presentation will provide a brief overview of these two theoretical frameworks, affirm the value of studying affect, and explore how researchers can utilize creativity to measure affective response.
\end{abstract}

KEYWORDS: affect theory, affect, expressive therapies continuum, research method, art, creativity, evangelical, women

\section{Introduction}

All human beings experience emotion to some degree. A vast array of research from social science fields, such as psychology, communications, and sociology, explain that emotions are a form of communication (Burgoon, Guerrero, \& Floyd 2016; Eaves \& Leathers 2017; Ekman 2003; Koppensteiner \& Siegle 2017; Mehrabian 2017; Sauter 2017). Art therapists in particular believe that artistic processes work to unearth emotions lying below conscious awareness (Moon 2016; Moon 2001). Art also helps articulate emotions of which one is aware but finds difficult to explain or process (Kalmanowitz \& Ho 2016; Moon 2011). Mental health fields demonstrate to other disciplines the importance of exploring, understanding, and utilizing emotion. If emotions communicate to, through, and from the body, then it is important to listen.

Mental health and psychological disciplines regularly discuss emotion, but how can emotion be elevated, discussed, and utilized among researchers? Some scholars have written about creative approaches to research (Cahnmann-Taylor \& Siegesmund 2017; Kara 2015), but many research guides do not include creative possibilities (Babones 2016; Bryman 2016; Elman, Gerring, \& Mahoney 2016; Miller \& Salkind 2002). If emotions communicate key aspects of the human experience, and the artistic process helps unearth, interpret, and express emotion, then does art not present itself as a viable tool for researchers seeking to understand emotion and impact?

There are two theories immensely useful in the pursuit to understand emotion and utilize art in research. The first is affect theory. Generally, affect theory "emphasizes correlations between nonlinguistic forces and power" and seeks to understand how people are emotionally influenced by the content exposed to them (Schaefer 2018, 68). This theory will be discussed extensively in this paper, so the term "affect" will be used primarily to describe emotion and both terms are considered interchangeable within the branch of affect theory utilized here. The second theory is the Expressive Therapies Continuum (ETC). If affect theory offers a framework for understanding how emotional responses are shaped and experienced, the Expressive Therapies Continuum (ETC) offers a way to 
visualize expression depending upon where affect situates in the body. As understood by the developers of the ETC, art therapists Sandra Kagan and Vija Lusebrink, the creation of artwork (of various types) taps into our kinesthetic-sensory, perceptual-affective, and cognitive-symbolic levels of information processing, where creativity serves as a mediator level for moving along these planes of the continuum (Hinz 2009; Kagan \& Lusebrink 1978).

These theories are combined in the study titled, "Female Evangelical Multimedia Personalities: How Does Their Content Affect Female Viewers?" This research study situates within a larger thesis project that is interested in prominent, public discourses in evangelicalism and their effect on young women in the United States. This study will expose participants to content from female evangelical authors (multimedia personalities) who publish in printed books, social media, blogs, and on websites. Participants will be asked to react artistically and verbally to written and visual evangelical content. In addition to gauging the affective experience of participants, this study seeks to illuminate how artistic processes expose the affective influence and power of rhetorical content. This paper explores affect theory, the ETC, and discusses the design and methods of this research study. Optimally, this paper will illuminate the importance of affect and provide evidence that the artistic process is a valuable research tool.

\section{Affect Theory}

Affect theory often focuses on the embodied experience of power through relationships with people, objects, language, and any interface that influences the body (Schaefer 2018). When we are affected by something, our bodies turn toward it, ascribe value, and allow it to shape us (Ahmed 2010). Affect theory highlights associations between the body and power and seeks to understand how content exposure influences the individual (Schaefer 2018). In Religious Affects: Animality, Evolution, and Power, Donovan Schaefer describes the relationship between affect and the human body as a spider web (Schaefer 2015, 98). Affect is an interwoven, interconnected, complex field of moving forces that acts as the foundation, the very groundwork, of the human body and experience (190). This web "carries his [subject's] existence," where the body is nestled into the web, stuck to it, but also everchanged by it as the web transforms through time (von Uexkull as cited in Schaefer 2015, 98). This paper relies heavily on the work of Schaefer who describes affect in navigable, visual, often metaphorical terms. The following is a breakdown of key affect theory components extracted from themes presented in Schaefer's work, utilizing other affect theorists to aid the exploration.

\section{Linguistic Fallacy}

Schaefer insists that we think beyond language. This does not mean language is not useful, necessary, or beautiful in its own right; but humans, particularly scholarly ones, often get stuck in language (Schaefer 2015, 189). Schaefer labels this the "linguistic fallacy," where language is presumed essential for profundity and power $(35,117)$. He pushes back on the assumption that "where bodies go is fundamentally determined by language," instead offering that it is an economy of affect, suffused by it $(117,202)$. In a poignant moment of visualization, Schaefer refers to language as "dropped on top of deep history, when bodies plunged into earth" (217). This understanding of language reverses the body's locus of control, offering a rawness to what lies at the bodily core. Rather than language driving bodies, affect interrupts this assumption and instead offers a model in which what a person feels is actually the running engine. Language, and involved cognitive processes, then flow out of affective spaces and bodies.

Schaefer holds emotions in such high regard because he believes even without language bodies would be relating and influencing one another in space. He suggests solitary confinement as an illustration. Schaefer cites an autobiography by Henri Charriere titled Papillon, explaining that prisoners in this confinement would try to manipulate guards into offering attention by causing trouble; negative attention was better than no contact at all (95). In this type of isolation, the fleshiness of the body returns, stripped away from all things that might cover the body, and it seeks out the senses above all else. Schaefer states bluntly, "Rather than mutilating bodies, solitary confinement mutilates affects" (93). Schaefer's establishment of the importance of the body and the 
way affect saturates language leads naturally into framing affective questions. When language and cognitive processes are no longer the sole controllers of the body, this crucially influences the way scholars and students develop questions and structure analysis.

\section{Framing Affective Questions}

Schaefer continually asks two questions that help reorient the body and mind around affect. He asks, "What do affects do?" and "What do bodies do for affects" (Schaefer 2015, 125). Another example is, "How do the words on the page induce a tissue of ideas, concepts, and beliefs to create emotions?" (Schaefer 2018, 87). These questions seek to position conversations about power in ways that again place the body at the center and questions whether or not bodies are in control of affect at all (125).

Viewing research through an affective lens, affective data comes to the forefront. This creates space for researchers to think creatively about how to collect affective data since it is not always easily discernible. Affect is complex, layered, and can be difficult to articulate. This requires researchers to acknowledge that affect is located in all parts of the body and to elicit affective data one may need to employ techniques that traverse beyond linguistic and cognitive processing.

\section{Power}

"Power make bodies move" (Schaefer 2015, 35). The way affect and power push and pull on bodies elicits an image of seaweed in a current - tossed, swirled, gently carried, ripped apart. Schaefer views power affectively, as if emotions that describe and surround the way bodies and systems relate represents the ultimate force of power. Affects, particularly religious affects, are binding (118). The "performative dimension of affect" serves "to in-struct or in-form (rather than merely reflect, record, or document) the felt sense of reality that structures our encounters with power" (67). Bodies are pulled and pushed by the current, but they are intimately changed and transformed in the process. Ideology becomes a "technology for the production of affect" (144). It is more than discursive or political; ideology, and the means used to convey it, actually exerts force on the body (Schaefer, 2018). The powerful affective utilization of ideology is also discussed by Bethany Moreton (2009), author of To Serve God and Walmart. In creation of employee culture, Walmart executives tapped into emotions and sentiments conveyed by local versions of Christianity. The administration aligned themselves with dominant local ideology, represented in ideals like "servant leadership," one of the organizational values (Moreton 2009, 115). The affective drives beneath this term encapsulate the desire for male Walmart employees to praise their wives' domestic work and to avoid "running the risk to share [work] equally," ensuring loyal and focused workers (115).

Humans regularly witness affect moving between, through, and around bodies. When happiness rises to the surface of the body in the form of laughter, or shame and guilt are conveyed through tears and slumped shoulders, other bodies witness and, at least partially, experience what they see. Sometimes this sharing of emotion becomes so electrically charged that tears or laughter flow from other bodies, caught in the current. This is powerful communication. If affect rumbles beneath language and bodies, this speaks volumes about how content exposure of all types enters this affectual current to influence and impact the whole person.

\section{Space}

In order to fully think about the way humans and affect relate, one must consider the importance of space. In the earlier example of solitary confinement, sensory deprivation shows how vital not only the materiality of space is but also the sensory relationship to space, including "colors, shapes, images, sounds, voices, motion, change" (Schaefer 2015, 100). Schaefer frequently refers to bodies as "tethered," or "affects as pulling on bodies even when the self is looking away" (103). This tethering can be both positive and negative. In the positive sense, it keeps bodies grounded, rooted, and helps to give shape and form. In the negative sense, tethering keeps people attached to harmful substances and dangerous behavior (105). Affect acts as an umbilical cord, providing source of life and necessary growth to the body. When this suddenly severs, the body cannot thrive and free floats in unfamiliar, ungrounded territory. Theorist Sara Ahmed discusses the way affect passes between bodies in her work 
on happiness. She states, "Thinking of affects as contagious does help us challenge an 'inside out' model of affect by showing how affects pass between bodies...however...to be affected by another does not mean that affect simply passes or 'leaps' from one body to another. The affect becomes an object only given the contingency of how we are affected, or only as an effect of how objects are given" (Ahmed 2010, 36). As discussed earlier regarding ideology, the vehicle used to pass and receive affect is deeply transformative.

Kathryn Lofton describes the affective space Oprah's products occupy in Oprah: Gospel of an Icon. She states, "Oprah...is always telling you what to do, always telling you how to do it...Even if you want to avoid her, even if you have avoided her, you have not (you cannot). She looms. She haunts the supermarket" (Lofton 2011, 8-9). Oprah's work represents an ever-present affect etched into words and marketing images, traveling into and around bodies, churning and transforming within the body only to emerge again.

These concepts elevate affect as the actual force moving in space, rather than solely words and concepts moving between minds. This means spaces and bodies hold emotions, continually transforming them and contributing to the current that pushes and pulls. Picture the person crying at the sight of their childhood home, or sites of public protest, affectively charged as tensions build. Visualizing the spatial quality of affect helps to keep it grounded in the body. Affects operate in and between human bodies and those bodies operate spatially. This is important to keep in mind for researchers studying people and their bodies existing in specific spaces.

\section{The Expressive Therapies Continuum}

As stated previously, the ETC (Figure 1) divides information processing into three levels: the sensorykinesthetic, affective-perceptual, and symbolic-cognitive (Hinz 2009, 5; Kagan \& Lusebrink 1978, 171; Lusebrink 2015, 58-60). Creativity then mediates the transition between levels. These levels correspond to various stages of human development. Each component of the ETC has a distinct "healing function" and guides and organizes therapeutic and creative processes (Hinz 2009, 8). Color and medium choice, strokes used to apply medium, the way an instrument is held (pencil, marker, brush, etc.), and graphics utilized in artwork are all reflective of a developmental stage, where a person rests on the ETC and manifest emotions (Hinz 2009, 15, 30). Artistic creation and medium help to facilitate an oscillation between stages on the ETC, moving back and forth from the sensory to the kinesthetic, the affective to the perceptual, and the symbolic to the cognitive (Hinz 2009; Lusebrink 2015, 61). The ultimate goal is that creativity will integrate the levels within the person, allowing that person to transition with relative ease along the entire continuum, from the kinesthetic to the cognitive and back as needed (Hinz 2009). One of the most recent, comprehensive and practical guides written about the ETC is Lisa Hinz's (2009) Expressive Therapies Continuum: A Framework for Using Art in Therapy. Figure 1 illustrates the ETC.

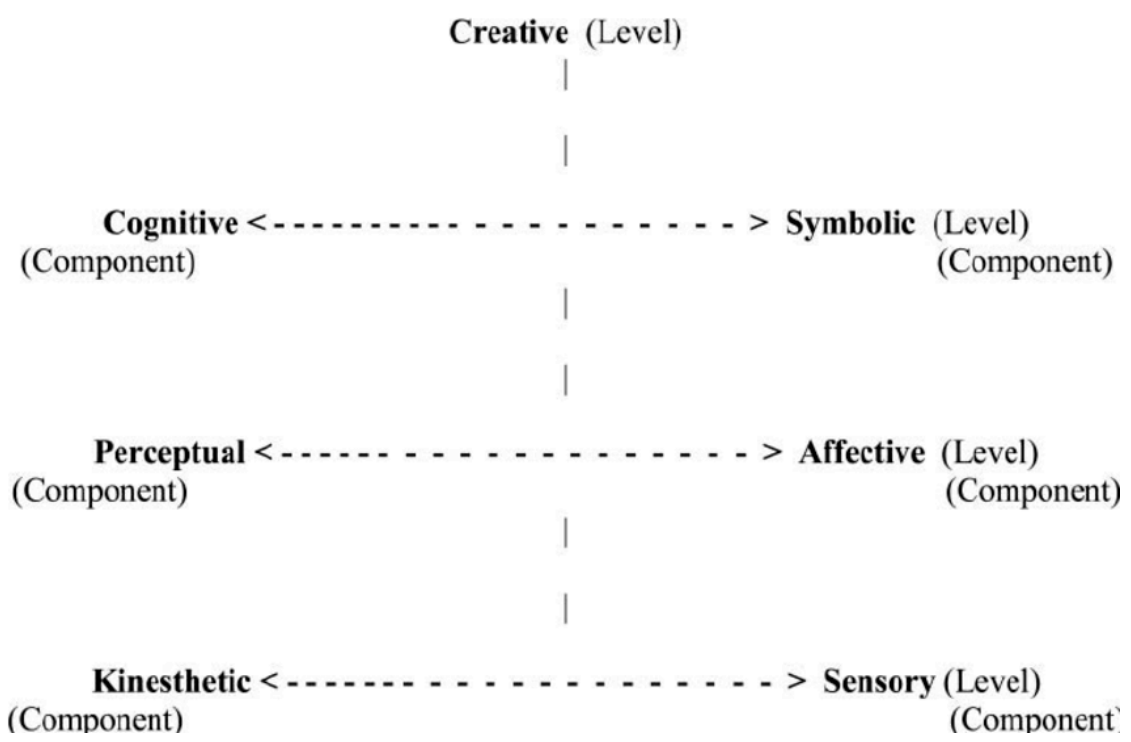

Figure 1. The Expressive Therapies Continuum (Hinz 2009, 5). 


\section{Levels}

The kinesthetic-sensory level represents the simplest and earliest forms of information processing. Kinesthetic-sensory processing and expression is "rhythmic, tactile, and sensual" (Hinz 2009, 6). Associated with the earliest stage of human development, it forms the foundation of memory. Media used to bring the body onto this level is chosen for its "sensual aspects," or to enable kinesthetic motion (Hinz 2009, 9).

The affective-perceptual level describes processing that may or may not express linguistically. Someone operating out of this level "can be emotional and raw, expressed in image without regard to form" (Hinz 2009, 6). Moving out of solely kinesthetic and sensory processing, forms start to surface. Those in the affective might be "caught up in emotion" or blinded by it (8). Shifting from perceptual to affective, forms may diminish and emotion dominates. This level can help enhance perspectives, increase empathy, healthily identify, process, and express emotions (10-11).

The cognitive-symbolic level is "complex and sophisticated" (Hinz 2009, 6). Operating out of this level requires "planning, cognitive action, and intuitive recognition" (6). Symbolic thought initiates access to intuition and recognizes that some experiences are mysterious and may not occur in the conscious mind. The cognitive offers "reality feedback" in all levels (12).

\section{Using the ETC}

Art therapists utilize various art media and techniques to unlock, elicit, or express affect. If an adult client operates primarily in the cognitive and has little interaction with the kinesthetic level, the therapist may choose to start a client with pencil drawing, a more restrictive medium. While the goal is to move a person along the continuum and tap into various levels of processing, the person must first start where they initially present on the continuum (Hinz 2009). Asking a person primarily operating out of the cognitive to finger paint may elicit an uncomfortable emotional response counterproductive to creative and healing processes. Similarly, asking a five-year-old child client to represent their emotions through symbols, and then provide solely pen and paper, is unlikely to spark creativity and may elicit confusion and frustration.

What can researchers learn from how art therapists use the ETC? First, understanding how affect, creativity, and bodily processing connect is crucial. For the researcher studying affect, it is not enough to state that affect is situated somewhere in the body and is expressed with the mind. The ETC and affect theory illustrate how complex and even creative the relationship is between the person and affect, requiring equally complex and creative methods to study and understand that relationship. This is not to say that traditional methods relying heavily on linguistic communication are not valuable and cannot reveal affective data. However, affect theory and the ETC point to a vast swath of affective data possibly lying just below the surface of what can be expressed linguistically. What if researchers more often combined verbal processing and creative processing in their measurements? What might this unearth?

\section{Research Study Design and Method}

Affect theory and the ETC are combined in the study "Female Evangelical Multimedia Personalities: How Does Their Content Affect Female Viewers?" to measure any possible impact this type of content has on female participants. As both of these theories indicate, affective forces and responses are crucial to the human experience. This study will attempt to elevate the affective voice utilizing both creative and verbal processing to measure participant experience.

\section{Content}

The desire to analyze the relationship between evangelicalism and public forms of communication is not new. From roadside attractions to Christian magazines to the evangelical roots of Wal-Mart, many authors have sought to unpack aspects of the Christian communications world (Beal 2005; Bielo 2018; Hendershot 2004; Moreton 2009). Research also reflects interest in how evangelical beliefs and principles influence evangelical women (Claney, Hall, Anderson, \& Canada 2018; Davis, Horrell, 
Anderson, \& Hall 2018; Griffith 1997; Stephan 2008), and explores the complex relationship between evangelical women and feminism (Creegan \& Pohl 2005; Hardesty 1999; Ingersoll 2003). Works on this topic represent a diverse group of theoretical frameworks, including grounded theory (Claney, Hall, Anderson, \& Canada 2018), feminist theory (Griffith 1997), theories of marketing and communications (Hendershot 2004; Lofton 2011), and a "religion-entertainment" framework (Bielo 2018, 176). To this author's knowledge, there has not yet been research that explores the influence of evangelical styles of communication and marketing through the lens of affect theory while also utilizing an expressive therapies theory. The tenets of affect theory offer a crucial framework for how to analyze whether the content of theologically conservative and liberal female multimedia personalities elicits a different affectual response in female viewers from ages 18-35.

While there are numerous evangelical authors in the public sphere, one way to measure influence is through online media presence. Conservative female authors like Lisa Bevere, Sarah Jakes Roberts, Joyce Meyers, and Beth Moore, and liberal female authors such as Sarah Bessey, Nadia Bolz-Weber, Rachel Held Evans, and Jamie Wright, have thousands (or in some cases millions) of Twitter and Instagram followers. These women have become multimedia personalities as their influence and authorship extends through published books, blogs, social media, podcasts, and some have trademarked ministries or curriculum geared toward the Christian lifestyle. These various forms of communication serve to spread either a conservative or liberal view of Christian belief, exploring themes like family, marriage, sexuality, devotion, worship, justice, and more (Bessey 2018; Bevere 2018; Bolz-Weber 2018; Held Evans 2018; Jakes Roberts 2018; Moore 2018; Meyer 2018; Wright 2018). Each personality utilizes marketing in a specific way, which unites the book, website, and blog, all reflecting the specific stylistic brand of the author. Research shows the way ideology is marketed and communicated matters to the way consumers receive, and possibly even believe, the message (Hendershot 2004; Moreton 2009; Lofton 2011). Research in sentiment analysis indicates that positive or negative sentiment is conveyed through textual and visual content in media (Ignatow \& Milhalcea 2018; Pozzi, Fersini, Messina, Liu 2017). This study seeks to focus in on how the sentiments and ideologies conveyed through this specific communications market impacts young female viewers.

\section{Design \& Methods}

This study is designed to operate in two parts. Participants will view the content of eight multimedia personalities, four of which represent conservative theology (Bevere, Jakes Roberts, Meyers, Moore) and four represent liberal theology (Bessey, Bolz-Weber, Held Evans, and Wright). The personalities were chosen based on substantial online influence and published material, measured mainly through social media presence and following.

In section one, participants will complete a brief baseline interview to disclose ethnicity, region of origin, religious affiliation, comfortability with art supplies, and how often (if at all) they read religiously themed material. They will also be asked to indicate their current affect (happy, sad, neutral, etc.) using Plutchik's color wheel before starting the research procedures.

Plutchik's wheel of emotion (Figure 2) will be utilized to assist participants in naming emotions (Plutchik 2001). This wheel, developed by Columbia University psychologist Robert Plutchik, outlines eight core emotions and closely associated variants (Plutchik 2001). The wheel assigns colors to each emotion and as the color intensifies so does the emotion. For example, while emotions related to "fear" are all green, a darker green is assigned to "terror" while a lighter shade is assigned to "apprehension" (Plutchik 2001, 348). A large body of research has utilized Plutchik's wheel to categorize and describe emotion, only a few of which are referenced here (Kamińska \& Pelikant 2012; Libert \& Tynski 2013; Loia \& Senatore 2014; Tromp \& Pechenizkiy, 2014). The wheel will help to prime participants for the art exercise where they will use color to express their experience. 


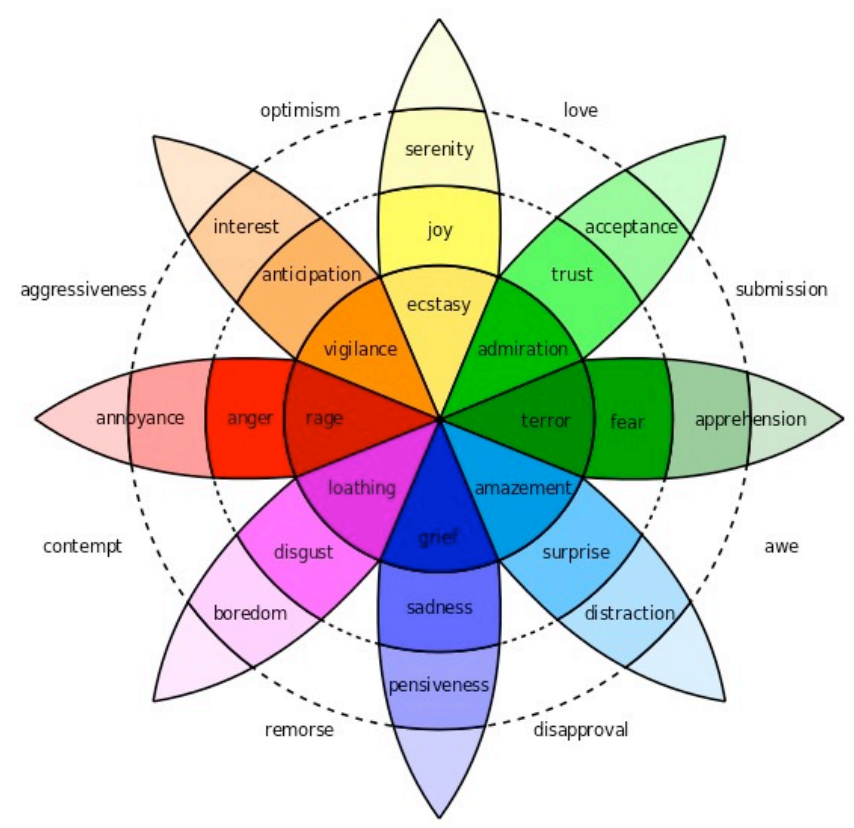

Figure 2. Plutchik's Wheel of Emotion

After establishing a baseline, participants will be presented with pre-selected excerpts from books, blog posts, social media posts, and online website pages from four conservative multimedia personalities. After participants read and view this material, they will be given a small blank canvas, acrylic paint, and a variety of tools with which to apply paint. Acrylic paint has been chosen in advance as the medium due to its' fluid quality and ability to invoke feeling. The ETC states that medium choice lies on a spectrum between fluid and resistive, fluid being those that invoke the most emotion and resistive being those that help to keep vulnerabilities below the surface. Acrylic paint lies comfortably on the fluid end to help unearth emotion without creating an overly raw emotional experience (Hinz 2009). Participants will be asked to paint symbols, images, or color fields of their choice on the canvas. They will then complete a brief questionnaire about their experience of reading this content.

For section two, all of these steps will repeat, substituting in liberal multimedia personality content. After completing both sections, there will be a closing interview to record final thoughts about the content and overall experience. They will also be asked to complete one last Plutchik's wheel to measure final affective state.

It is important to note that participants will be provided a resource sheet with contact information for nearby mental health resources should they find the need to speak with someone about their experience or to further process any emotional response. Whenever researchers or other professionals seek to unearth emotional responses, resources to attend to these responses should always be provided.

\section{Analysis}

Descriptive statistics will be used to describe and categorize the sample of participants. The bulk of analysis will be qualitative, where the interview, questionnaire, and artistic responses will be analyzed in the context of the sample utilizing the theoretical frameworks outlined previously. Art therapy resources, such as the work of Lisa Hinz, can help guide analysis of artwork, looking carefully at color choice, symbols, line weight, image content, choice of paint application tool, and more. Written analysis will compare variation in responses (verbal and artistic) depending on the precipitating content.

This study also lends well to utilizing topic modeling tools to enrich analysis. Entering the same content that participants will be viewing through a topic modeling software might show what a machine observes about the content versus what participants perceive. This could further enhance discovery related to content exposure. 


\section{Limitations}

As evidenced by affect theory and the ETC, affect is complex, ever-changing, and cannot be measured fully in a brief timespan. This study will attempt to measure a glimpse of what is happening in the moment for participants, but recognizes that time constraints limit what can be measured. Future studies might alter the medium choice, or offer a variety of media to choose from, which might offer additional insights. The sample size for this study will be small and regionally located, and therefore not generalizable to larger populations.

\section{Conclusion}

Affect theory and the ETC as outlined here highlight how multifaceted, transformative, and crucial affect is to the human experience. Ideological content is just one example of ways humans are influenced and impacted on a daily basis. This exploration of theory and research methodology expresses one possible way of creatively measuring affect. If these theories teach nothing else, they show that creativity inspires the body to operate on other levels of creativity; in service of affect, utilizing creative processes in research can only further enrich analysis.

\section{Acknowledgments}

I would like to thank the Religious Studies Department at Case Western Reserve University for their generous support in attending this conference and in offering continuous support during my graduate career. I am especially grateful to my graduate advisor, Dr. Timothy Beal, who has guided the development of this project since the beginning.

\section{References}

Ahmed, Sara. 2010. "Happy Objects.” In The Affect Theory Reader, edited by Gregory J. Seigworth \& Melissa Gregg, 29-51. Durham, NC: Duke University Press.

Beal, Timothy. 2005. Roadside Religion: In Search of the Sacred, the Strange, and the Substance of Faith. Boston: Beacon Press.

Bessey, Sarah. 2018. "Sarah Bessey. Available at " http://sarahbessey.com/.

Bevere, Lisa. 2018. "Messenger International." Available at https://messengerinternational.org/lisabevere/.

Bielo, James. 2018. Ark Encounter: The Making Of A Creationist Theme Park. New York: New York University Press.

Bolz-Weber, Nadia. 2018. "Nadia Bolz-Weber." Available at http://www.nadiabolzweber.com/.

Bryman, Alan. 2016. Social Research Methods. Oxford, UK: Oxford University Press.

Burgoon, Judee K., Laura K. Guerrero, and Kory Floyd. 2016. Nonverbal Communication. New York, NY: Routledge.

Cahnmann-Taylor, Melisa, and Richard Siegesmund, eds. 2017. Arts-Based Research in Education: Foundations For Practice. New York, NY: Routledge.

Claney, Carly J., M. Hall, Tamara L. Anderson, Andrea Canada. 2018. "Sexual Without Sex: A Qualitative Study of Single Emerging Adult Evangelical Women." Psychology of Religion and Spirituality.

Creegan, Nicola Hoggard, and Christine D. Pohl. 2005. Living on the Boundaries: Evangelical Women, Feminism and the Theological Academy. Downers Grove, IL: InterVarsity Press.

Davis, Jaclyn M., Kerry E. Horrell, Tamara L. Anderson, and M. Elizabeth Lewis Hall. 2018. "Religious and Role Contributions to the Marital Satisfaction of Evangelical Women." Journal of Psychology and Theology 46 (3): 184-198.

Eaves, Michael, and Dale G. Leathers. 2017. Successful Nonverbal Communication: Principles and Applications. New York, NY: Routledge.

Ekman, Paul. 2003. Emotions Revealed: Recognizing Faces and Feelings to Improve Communication and Emotional Life. New York, NY: Henry Holt and Company, LLC.

Evans, Rachel Held. 2018. "Rachel Held Evans ". Available at https://rachelheldevans.com/.

Griffith, R. Marie. 1997. God's Daughters: Evangelical Women and the Power of Submission. Berkeley and Los Angeles, CA: University of California Press.

Hardesty, Nancy. 1999. Women Called To Witness: Evangelical Feminism in the Nineteenth Century (2nd ed.). Knoxville, TN: University of Tennessee Press.

Hendershot, Heather. 2004. Shaking the World for Jesus: Media and Conservative Evangelical Culture. Chicago, IL: University of Chicago Press.

Hinz, Lisa. 2009. Expressive Therapies Continuum: A Framework for Using Art in Therapy. New York, NY: Routledge.

Ignatow, Gabe, and Rada Mihalcea. 2017. An Introduction to Text Mining: Research Design, Data Collection, and Analysis. Thousand Oaks, California: SAGE Publications, Inc. 
Ingersoll, Julie. 2003. Evangelical Christian women: War stories in the gender battles. New York: New York University Press.

Kagin, Sandra L., and Vija B. Lusebrink. 1978. The Expressive Therapies Continuum. Art Psychotherapy, 5(4): 171180. Doi:https://doi.org/10.1016/0090-9092(78)90031-5

Kalmanowitz, Debra, and Rainbow T.H. Ho. 2016. "Out Of Our Mind. Art Therapy and Mindfulness with Refugees, Political Violence and Trauma." The Arts In Psychotherapy 49: 57-65.

Kamińska, Dorota, and Adam Pelikant. 2012. "Recognition of human emotion from a speech signal based on plutchik's model." International Journal of Electronics and Telecommunications, 58(2): 165-170. Doi:10.2478/v10177012-0024-4

Kara, Helen. 2015. Creative Research Methods in the Social Sciences: A Practical Guide. Bristol, UK: Policy Press.

Koppensteiner, Markus, and Greg Siegle. 2017. "Speaking Through the Body." Politics \& the Life Sciences 36(2): 10413. Doi:10.1017/pls.2017.23.

Libert, Kelsey, and Kristin Tynski. 2013. "The Emotions That Make Marketing Campaigns Go Viral." Harvard Business Review 1, no. 1.

Lofton, Kathryn. 2011. Oprah: The Gospel of an Icon. Berkeley, CA: University of California Press.

Loia, Vincenzo, and Sabrina Senatore. 2014. "A Fuzzy-Oriented Sentic Analysis to Capture the Human Emotion In Web-Based Content.” Knowledge-Based Systems, 58: 75-85. Doi:10.1016/j.knosys.2013.09.024.

Lusebrink, Vija B. 2015. "Expressive Therapies Continuum." The Wiley handbook of art therapy, 57-67.

Mehrabian, Albert. 2017. Nonverbal Communication. New York, NY: Routledge.

Meyers, Joyce. 2018. "Joyce Meyer Ministries: Sharing Christ - Loving People." Available at https://www.joycemeyer.org/.

Miller, Delbert C., and Neil J. Salkind. 2002. Handbook of Research Design and Social Measurement. Thousand Oaks, CA: Sage Publications, Inc.

Moon, Bruce L. 2016. Art-Based Group Therapy: Theory and Practice. Springfield, IL: Charles C Thomas Publisher.

Moon, Catherine Hyland, ed. 2011. Materials and Media in Art Therapy: Critical Understandings of Diverse Artistic Vocabularies. New York, NY: Routledge.

Moore, Beth. 2018. "Living Proof Ministries." Available at https://www.lproof.org/.

Moreton, Bethany. 2009. To Serve God and Wal-Mart. Cambridge, MA: Harvard University Press.

Plutchik, Robert. 2001. “The Nature of Emotions.” American Scientist, 89(4): 344. Doi:10.1511/2001.4.344.

Pozzi, Federico Alberto, Elisabetta Fersini, Enza Messina, and Bing Liu. 2016. Sentiment Analysis in Social Networks. Cambridge, MA: Morgan Kaufmann.

Roberts, Sarah Jakes. 2018. "SJR: Sarah Jakes Roberts." Available at http://sarahjakesroberts.com.

Sauter, Disa A. 2017. "The Nonverbal Communication of Positive Emotions: An Emotion Family Approach." Emotion Review 9(3): 222-234.

Schaefer, Donavan. 2018. "Beautiful Facts: Science, Secularism, and Affect." In Feeling Religion, edited by Corrigan, 69-92. Durham, NC: Duke University Press.

Schaefer, Donovan. 2015. Religious Affects: Animality, Evolution, and Power. Durham, NC: Duke University Press.

Stephan, Scott. 2011. Redeeming the Southern Family: Evangelical Women and Domestic Devotion in the Antebellum South. Athens, GA: University of Georgia Press.

Tromp, Erik, and Mykola Pechenizkiy. 2014. "Rule-based emotion detection on social media: putting tweets on plutchik's wheel." arXiv preprint arXiv:1412.4682.

Wright, Jamie. 2018. The Very Worst Missionary: A Memior or Whatever. New York, NY: Convergent Books. 